\title{
Chapter 1 \\ Ongoing Advancements in ICT and the Need for Holistic Strategic Management
}

\begin{abstract}
Technological convergence in different professional areas with advanced ICT has become a crucial research issue in the field of technology and innovation management (TIM) and has also become a major factor causing radical innovation that leads to the creation of brand-new markets. Technological convergence has been described as the combination of technical knowledge across clearly definable areas of specialization, in particular in the context of ICT. The utilization of ICT across various industries and the integration of dissimilar technologies accelerate convergence and increase the potential to develop new products and services through co-specialization and new business models that span different industries. Responding to these environmental changes, corporations are under increasing pressure to execute dynamic reconfiguration (redefinition of their vertical and horizontal boundaries) to optimize their corporate boundaries by accelerating coordination and collaboration between disparate companies and businesses through collaborative innovation (CI).

To dynamically optimize corporate boundaries with convergence such as that described above, a holistic approach for strategic management is crucial. This is a key concept in this book. Focusing on holistic systems theory, this chapter argues that building a framework for holistic strategic management requires elements of management similar to those in strategic management (strategy, organizations, technologies, operations, leadership) and analysis of synergistic interactions among these as well as an interactive and back-and-forth analysis and study at the macro and micro levels of strategic and organizational contexts of corporations, including their advanced ICT environments in particular.

Keywords: Technological convergence, holistic strategic management, ICT, IoT, co-specialization
\end{abstract}




\subsection{Introduction - The Era of Advanced ICT and Convergence}

IoT, AI, big data and robots contribute to further advancements in conventional internet technologies. The technical revolution of this advanced ICT is bringing about unprecedented impacts and speeds. The IoT enables two-way exchanges of all kinds of information in society via the internet, while big data technologies collect and analyze massive amounts of data (e.g., IoT/M2M data, cloud computing information, SNS data, real and virtual commercial information and location information), thus creating a new value in tangible forms. In addition, deep learning, which is driving the rapid growth of AI, empowers AI to learn on its own and make highlevel judgments and decisions beyond the capabilities of ordinary humans. Furthermore, various robotic technologies enable the automation of a wide range of complex tasks, which not only increases efficiency in business but also enables the achievements in society previously thought to be impossible.

A major topic in the ICT industry in developed countries at present is the provision of integrated services through IoT and AI. As advanced sensor technologies and low-power, wide-area (LPWA) technologies suitable for IoT services emerge, communication methods diversify. Industries in Europe are capitalizing on their manufacturing know-how and absorbing net technologies to expand new services from the real to the net. Simultaneously, they are broadening development from the net to the real with the expansion of cloud services by absorbing real-space information as well as information on the internet centered on U.S. IT companies. In Japan, the so-called fourth Industrial Revolution (Society 5.0) aims to achieve "an ultra-smart society" through the integration of the net and the real, and unification of industry and academia (see Figure 1.1).

These technical innovations have the potential to dramatically change the structures of industry and employment. From the uniform services of conventional mass production, these technical innovations have the potential to radically improve efficiency and productivity across entire supply chains by providing products customized to suit individual user needs and by sharing data in real time. In the future, advanced ICT will create new markets by combining core technologies and business models of various 


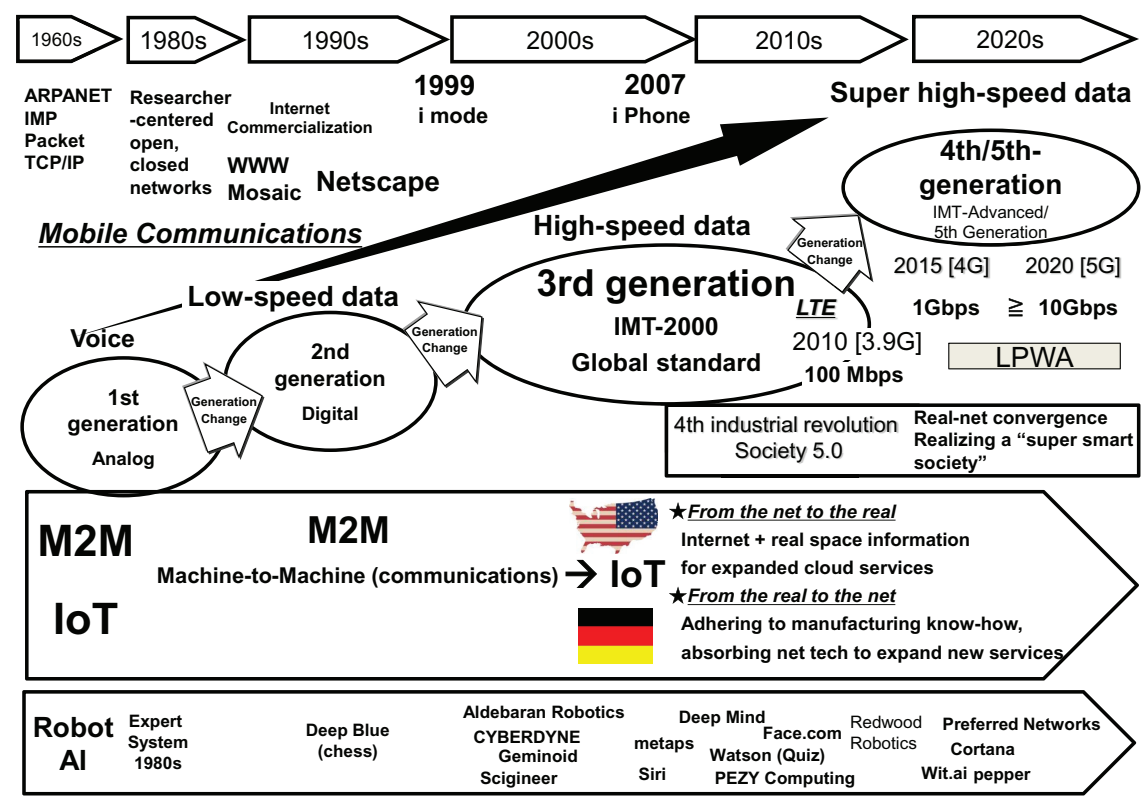

Fig. 1.1. ICT advances and innovation.

disparate fields as common platforms (platform technologies) for technical revolution in all industries. For example, the convergence of genome-editing technologies and various biological data with advanced ICT will bring about new development in pharmaceuticals, agriculture and bioenergy.

In particular, advances in IoT are driving the networking of products among dissimilar products and industries and dramatically expanding individual product functionality. This networking is organically combining core technologies and individual business processes in wide-ranging industries with a diversity of big data sent and received in real time from people and things across various professional areas. Hence, the once clearly delineated boundaries between products and industries are becoming blurred, and the potential for new boundaries to form is increasing. In IoT, the focus needs to be on the acceleration of co-specialization (to be discussed later) as the creation of new business models such as services or integrated systems ${ }^{1}$ through synergies between different products and industries enabled by networking and the convergence of things, people, data, technologies and processes (see Figure 1.2). 
Co-specialization: co-specialization of assets with other assets, of strategy and structure, of strategy and processes etc.

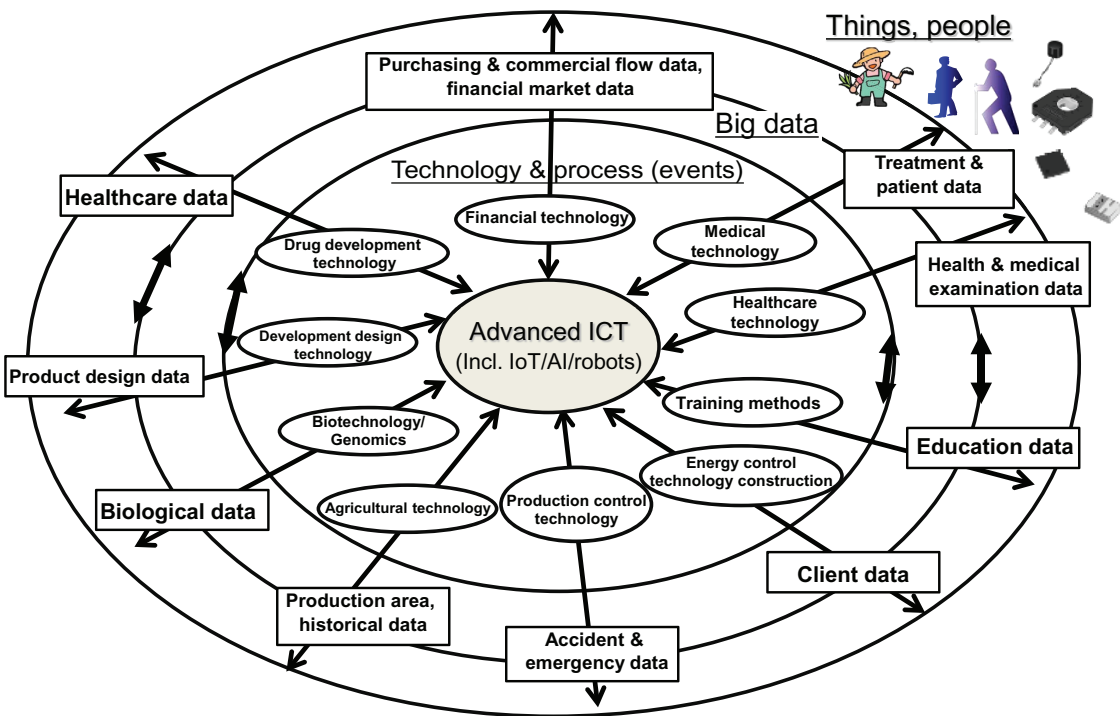

Fig. 1.2. Co-specialization through convergence.

Technological convergence in these different professional areas with advanced ICT has become a hot topic in the field of technology and innovation management (TIM). This has also become a major factor bringing about radical innovation and creating brand-new markets (e.g., Duysters and Hagedoorn, 1998). Technological convergence has been defined as the combination of technical knowledge across clearly definable areas of specialization, particularly in the context of ICT (e.g., Gambardella and Torrisi, 1998).

Technological convergence occurs through the merging of knowledge of different areas of specialization (knowledge convergence process) (Kodama, 2005; Hacklin, 2008; Harianto and Pennings, 1994) at a level that encompasses different areas of expertise (Kodama, 2005; Fleming and Sorenson, 2004). Therefore, to make technological convergence successful, it stands to reason that integration (fusion) of knowledge encompassing different areas of technical expertise is a crucial factor in business (Kodama, 2005, 2009a, 2011a, 2011b). 


\subsection{Convergence Accelerates the Co-specialization Process}

Convergence causes the traditional knowledge of various industries and specializations to become obsolete and drives incremental and radical innovation for new knowledge convergence through learning and innovation activities of groups and organizations as well as individuals (Kodama, 2005; Fleming and Sorenson, 2004). This convergence is a factor that drives the formation of company and organization networks and mergers and acquisitions through strategic alliances formed between different corporations, and between different business sectors and industries (Kodama, 2009b, 2014, 2015; Hacklin, 2008; Harianto and Pennings, 1994). Existing research has analyzed and studied processes in which technologies are duplicated (Mowery, Oxley and Silverman, 1996) as relative factors of partnerships between corporations or mergers and acquisitions, and technological convergence as variables causing effects in the flow of knowledge between companies (Corredoira and Rosenkopf, 2010) and within organizations (Bosch, Volberda and Boer, 1999), or the relationship of market structural factors with network resources under conditions in which convergence exists (Lee, 2007).

Innovation with this convergence offers new insights and implications for knowledge creation theory (Nonaka and Takeuchi, 1995) and in the TIM field. In the ICT industry in particular, causing technological convergence across entire industries (Kodama, 2002; D'Aveni, Dagnino and Smith, 2010; Hacklin, 2010; Zhang and Li, 2010) can act as a major trigger in the formation of business ecosystems that incorporate new business environments and markets, and involve a large number of companies (Kodama, 2009b; Ghoshal and Bartlett, 1994).

In addition, according to the dynamic capabilities (DCs) of Teece (2007) based on evolutionary economics (Nelson and Winter, 1982), coevolution is possible in well-coordinated forms with other assets because many intangible assets are highly specific. Hence, there is potential for a company to create high value by creating special positions derived from assets co-specialized by combining and reconfiguring various intangible assets. Co-specialization has significant importance in corporate strategy, and the systems of many high-tech products and services, as technological 
convergence brought about by advanced ICT, as shown in Figure 1.2, achieves co-specialization among multiple assets. These systems can also be said to be co-specialized assets that consist of interdependent elements supported by the platforms of advanced ICT.

In competitive environments such as that of the ICT industry in which global businesses are expanding and horizontal divisions of labor are accelerating, it is crucial that companies continually demonstrate capabilities for integrating various assets to build and actuate co-specialization of global systems. Thus, for companies, this means increasing importance of the need to combine assets among companies cooperating and collaborating with each other to provide new customer value through co-specialization. In other words, this is the importance of "collaborative innovation" (CI) (Kodama, 2011b, 2015).

However, CI includes not only the aspect of "collaborative innovation defined here as a development process of new and useful products and services across and outside company boundaries" cited by Haefliger (2012, p. 2), but in the broader sense, it also includes CI within companies (including group and affiliate companies), which transcend internal boundaries across a range of organizations and areas of specialization. Hence, CI involves innovation processes through the formation of "innovation networks" (including networks built using ICT) (Kodama, 2009b) across a range of specialties, business segments and functions, enterprises and industrial fields within and between companies (or organizations), and between companies (organizations) and their customers. From the perspective of inspiration, transfer, sharing, use and creation of diverse knowledge including intellectual property, it is necessary not only to further drive the conventional "closed innovation" (Kodama, 2011b) within a company or organization but also to drive "open innovation" and "hybrid innovation" as a combination of closed and open innovation as corporate (organization) activities. Forming these wide-ranging innovation networks (or knowledge networks - company's internal knowledge networks or external knowledge networks) enables the convergence (integration) of diverse knowledge through CI both within and outside companies, including their customers. Accordingly, academic research into the macro and micro processes involved in the instigation, maintenance and development of CI from the strategic and organizational perspective has become an important issue. 
Teece (2012) also asserts that entrepreneurship in top management is necessary for the management of co-specialization. Entrepreneurship, according to Teece, means sensing opportunities for convergence, understanding them, initiating action, and discovering new and better methods for combining all elements, which can also mean creatively coordinating and combining dissimilar elements to enable co-specialization. Entrepreneurial management has almost no relationship (requirement) with standardized analysis or optimization. Perceiving the next big (potential) opportunities and issues as they emerge and devising methods to deal with them are more important than maintaining and refining existing methods. As Teece (1986) noted, the conventional influence of economies of scale and scope on the definitions of corporate boundaries is weakening, while economies of co-specialization are affecting the definitions of corporate boundaries, as discussed in Section 1.3.

\subsection{Dynamic Optimization of Corporate Boundaries for Convergence}

With rapidly evolving technologies, shortened product life cycles, mature markets in developed countries, expanding markets in developing countries and ongoing advances in ICT in recent years, many companies are faced with the challenge of having to develop new technologies and configure new business models. From the point of view of sustainable corporate growth, cleverly combining highly original and new knowledge with products, services and business models enables the creation of new markets and raises the potential for enhanced business performance (Grant, 1996a, 1996b; Kodama, 2009a).

For example, with the commercialization of their i-mode, iPod and iTunes/iPhone products, NTT DOCOMO and Apple are companies that have mastered capabilities for integrating internet technologies, diverse software technologies, and various applications and contents based on mobile communication technologies to bring about new value chains and business ecosystems to achieve greater value than their existing products through co-specialization (Kodama, 2002, 2011b).

According to existing research, integrating knowledge that is separated by substantive boundaries, in other words bringing together technical 
knowledge that has little or no relationship with other existing knowledge knowledge in isolated technical areas - has much greater potential in bringing about new and innovative achievements than reliance on more close-knit or path-dependent knowledge (Kodama, 2002, 2011a, Nesta and Saviotti, 2006; Fleming and Sorenson, 2004; Katila and Ahuja, 2002; Rodan and Galunic, 2004; Zahra, 2008). However, fusing knowledge isolated by boundaries is an extremely challenging proposition, and the management of required innovation processes is fraught with difficulties involving personnel, capital, risks and uncertainty (Kodama, 2011a, 2011b; Grant, 1996a; Kodama and Shibata, 2014). In spite of this, recent years have seen an increasing need to merge isolated knowledge across boundaries.

In actual fact, the integration of knowledge separated by boundaries (Kodama, 2009a, 2011a, 2011b; Zahra, 2008; Hacklin, Marxt and Fahrni, 2009) has resulted in the emergence of new technical fields such as nanobiotechnology (Roco, 2003; Shmulewitz, Langer and Patton, 2006), ICT-centered mobile internet using mobile phones (Kodama, 2002), application and contents businesses with smartphones (Kodama, 2009b, 2011b), e-healthcare (Kodama, 2015) and connected vehicles (Kodama, 2011b). Raising the capabilities of individuals and organizations working across boundaries between different specializations drives integration of knowledge across boundaries and becomes an important trigger for acquiring competitiveness (Kodama, 2002, 2007; Nesta and Saviotti, 2006; Carlile, 2004). However, there has been little research to date in this field in spite of the dramatic impacts convergence is having on the knowledge of individuals and organizations and the organizational capabilities of companies and entire industries.

ICT utilization across various industries and integration of dissimilar technologies accelerates convergence and raises the potential to bring about new products and services through co-specialization and new business models that span different industries. Responding to these environmental changes, corporations are under increasing pressure to execute dynamic reconfiguration (redefinition of their vertical and horizontal boundaries) to optimize their corporate boundaries by accelerating coordination and collaboration between different companies and businesses through CI (see Figure 1.3). 
[Merging different technologies and industries, advancing ICT]
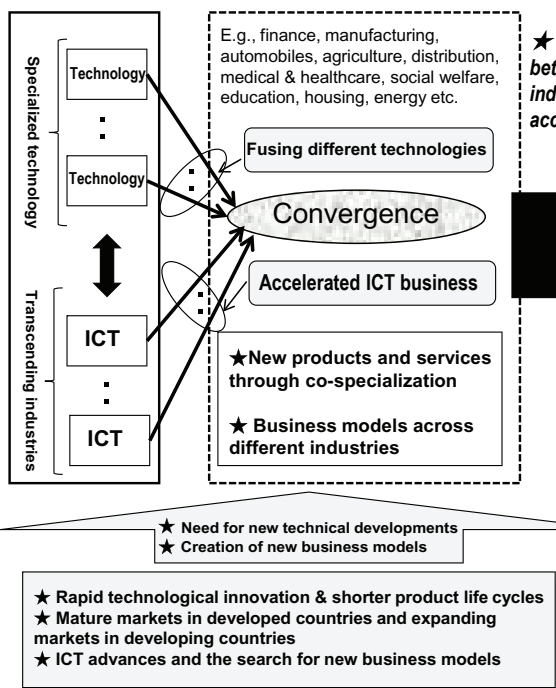

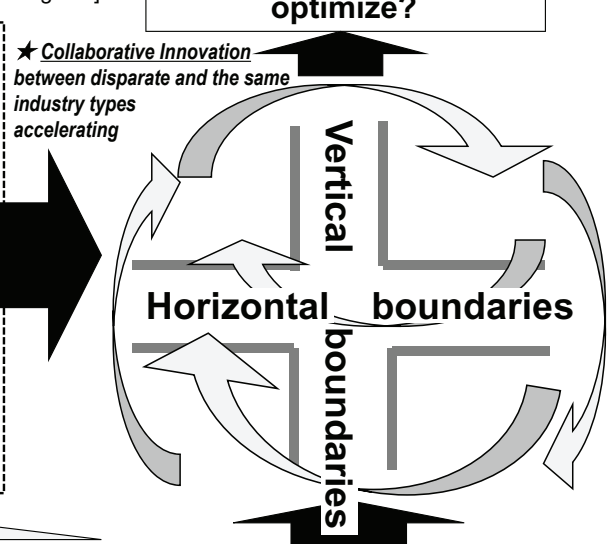

Dynamic reconfiguration of corporate boundaries

$\star$ Redefining new vertical boundaries

$\star$ Redefining new horizontal boundaries

Fig. 1.3. Dynamic optimization of corporate boundaries adapted to convergence.

To dynamically optimize corporate boundaries with convergence as described above, the central "holistic approach for strategic management" concept of this book is crucial. Based on holistic systems theory, the construction of a framework for holistic strategic management entails management factors closely related to strategic management (strategy, organizations, technologies, operations, leadership) and analysis of the synergistic interactions among these, as well as interactive and back-andforth analysis and study at the macro and micro levels regarding the strategic and organizational contexts of corporations, including their advanced ICT environments in particular.

\subsection{Conceptual Framework of the Book - A Holistic View of Strategic Management}

Applying both innovation theory and capabilities theory, this book presents a new framework and knowledge for "holistic strategic management" from a systems theory lens that focuses on the issue of how major 
corporations can develop capabilities to achieve strategic innovation in response to the impacts of advanced ICT on corporate management. "Holistic strategic management" refers to a strategic management framework for achieving ongoing strategic innovation through the establishment of a strategic innovation system (SIS) and interaction (environment creation and environment adaption) with the environment (market, technology, ecosystems, e.g., advanced ICT) (see Figure 1.4).

A brief survey of large corporations at the global level today indicates that many have not been particularly successful at strategic innovation. One reason achieving innovation is difficult is the insufficient understanding at a practical level that the mechanisms which promote the processes of innovation and the organizational capabilities within a company comprise a complex system consisting of independent elements. Therefore, from an academic research perspective, a holistic approach is necessary for a company to systematically develop and internalize capabilities for

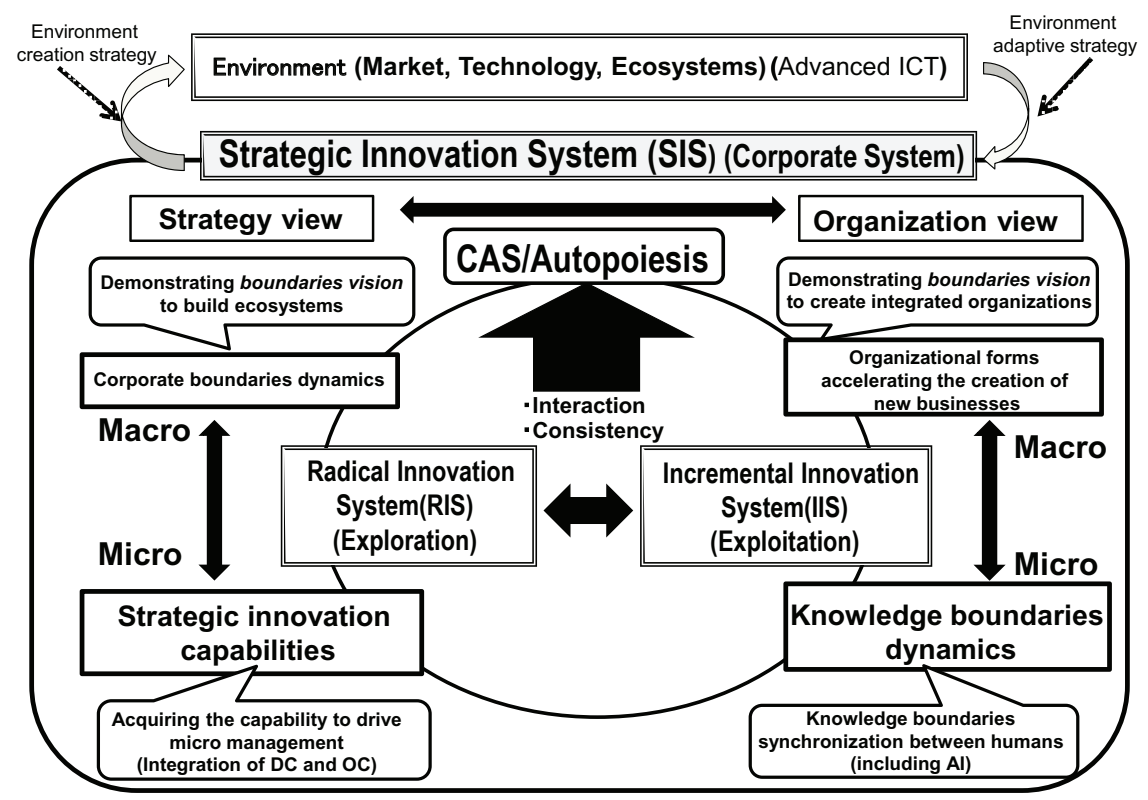

Fig. 1.4. A holistic view of strategic management. 
the ongoing achievement of strategic innovation and to deepen its understanding of the ideal methods of implementing strategic management for building an SIS as a corporate system. Therefore, analyzing the mechanisms of this complex strategic innovation and SISs through a system theory lens is of considerable importance for the researcher.

Drawing from existing research on innovation theory, capabilities theory and systems theory, the book identifies the elements of subsystems (radical innovation system or RIS and incremental innovation system or IIS) comprising a corporate system for generating sustained strategic innovation from the management contexts of strategy, organizations, technologies, operations and leadership, and it clarifies the interaction between and among the subsystems. The book also offers propositions for building SISs for guaranteeing sustained corporate growth based on knowledge of systems theory, such as complex adaptive systems (CAS) and autopoiesis (see Figure 1.4).

In addition, the book constructs a framework for a corporate strategy that adapts to evolving convergence in an advanced ICT era from the strategic context of the macro and micro views of the "dynamics of corporate boundaries" and "organizational capabilities" of both individuals and organizations driving the corporate strategy, as well as the macro and micro interaction of these. In particular, convergence accelerates CI (Kodama, 2015) by people, organizations, companies and industries, and enhances the potential for creating new business ecosystems through the dynamic reconfiguration of corporate boundaries. Furthermore, from a macro-strategy viewpoint, the book points to the importance of the "creativity view" and "dialectical view" of stakeholders in regard to boundary conceptions as elements that determine corporate boundaries.

From a micro-strategy viewpoint, the book indicates the importance of strategic innovation capabilities (SICs) as organizational capabilities which adapt to changes in the environment (either actively or passively) as convergence. Arguing that DCs and ordinary capabilities should be integrated as SICs rather than maintained as separate entities (Teece, 2014), the book adds a new perspective to existing research.

At the same time, from a macro-organization viewpoint, the book discusses the integrated organization formed from both old and new 
organizations, which accelerates new business creation by adapting to evolving convergence. In addition, from a micro-organization viewpoint, it presents the characteristics of and new theory on the dynamics of knowledge boundaries between actors (including artificial intelligence) and discusses innovation processes that drive convergence. These microknowledge boundaries have an impact on both the formal organization and informal organization at the macro level and provide viewpoints that have a significant impact on the knowledge convergence (integration) process (Kodama, 2011a, 2014). Furthermore, the book introduces "boundary synchronization" as a new concept for integrating knowledge that spans different fields of specialization to achieve technological convergence (see Figure 1.4). It also indicates that "boundary vision" (Kodama, 2011b, 2014, 2018; Kodama and Shibata, 2016) is essential as a cognitive capability for driving the thinking and behavior of practitioners in terms of their strategy view and organization view, which are alternating between the macro and micro views, and integrate the two (see Figure 1.4).

As described above, the book presents new knowledge and insights from the lens of holistic systems theory across a management context of strategy, organizations, technologies, operations and leadership related to strategic management. Finally, through comparative analysis of in-depth case studies of a number of global corporations, the book presents a refinement of a holistic framework for strategic management as well as new academic knowledge and implications including practical implications for practitioners.

\section{References}

Carlile, P. (2004). Transferring, translating, and transforming: An integrative framework for managing knowledge across boundaries. Organization Science, 15(5), pp. 555-568.

Corredoira, R. A. and Rosenkopf, L. (2010). Should auld acquaintance be forgot? The reverse transfer of knowledge through mobility ties. Strategic Management Journal, 31(2), pp. 159-181.

D'Aveni, R. A., Dagnino, G. B. and Smith, K. G. (2010). The age of temporary advantage. Strategic Management Journal, 31(13), pp. 1371-1385. 
Duysters, G. and Hagedoorn, J. (1998). Technological convergence in the IT industry: The role of strategic technology alliances and technological competencies. International Journal of the Economics of Business, 5(3), pp. 355-368.

Fleming, L. and Sorenson, O. (2004). Science as a map in technological search. Strategic Management Journal, 25(8-9), pp. 909-928.

Gambardella, A. and Torrisi, S. (1998). Does technological convergence imply convergence in markets? Evidence from the electronics industry. Research Policy, 27(5), pp. 445-463.

Ghoshal, S. and Bartlett, C. A. (1994). Linking organizational context and managerial action: The dimensions of quality of management. Strategic Management Journal, 15(S2), pp. 91-112.

Grant, R. M. (1996a). Prospering in dynamically competitive environments: Organizational capability as knowledge integration. Organization Science, 7(3), pp. 375-378.

Grant, R. M. (1996b). Toward a knowledge-based theory of the firm. Strategic Management Journal, 17(Winter Special Issue), pp. 109-122.

Hacklin, F. (2008). Management of Convergence in Innovation: Strategies and Capabilities for Value Creation beyond Blurring Industry Boundaries. Contributions to Management Science. Heidelberg: Physica-Verlag.

Hacklin, F., Marxt, C. and Fahrni, F. (2009). Coevolutionary cycles of convergence: An extrapolation from the ICT industry. Technological Forecasting and Social Change, 76(6), pp. 723-736.

Hacklin, F. and Wallin, M. W. (2013). Convergence and interdisciplinarity in innovation management: A review, critique, and future directions. The Service Industries Journal, 33(7-8), pp. 774-788.

Haefliger, S. (2012). Collaborative Innovation - Strategy, Technology and Social Practice, PhD Thesis, ETH Zurich.

Harianto, F. and Pennings, J. M. (1994). Technological convergence and scope of organizational innovation. Research Policy, 23(3), pp. 293-304.

Katila, R., \& Ahuja, G. (2002). Something old, something new: A longitudinal study of search behavior and new product introduction. Academy of Management Journal, 45(6), pp. 1183-1194.

Kodama, M. (2002). Transforming an old economy company through strategic communities. Long Range Planning, 35(4), pp. 349-365.

Kodama, M. (2005). Knowledge creation through networked strategic communities: Case studies in new product development. Long Range Planning, 38(1), pp. 27-49. 
Kodama, M. (2007). Project-Based Organization in the Knowledge-Based Society. London, UK: Imperial College Press.

Kodama, M. (2009a). Boundaries innovation and knowledge integration in the Japanese firm. Long Range Planning, 42(4), pp. 463-494.

Kodama, M. (2009b). Innovation Networks in the Knowledge-Based Firm. UK: Edward Elgar Publishing.

Kodama, M. (2011a). Knowledge Integration Dynamics - Developing Strategic Innovation Capability. Singapore: World Scientific Publishing.

Kodama, M. (2011b). Interactive Business Communities - Accelerating Corporate Innovation through Boundary Networks. UK: Gower Publishing. Kodama, M. (2014). Winning Through Boundaries Innovation - Communities of Boundaries Generate Convergence. UK: Peter Lang.

Kodama, M. (Ed.) (2015). Collaborative Innovation: Developing Health Support Ecosystems, Vol. 39. UK: Routledge.

Kodama, M. (2018). Sustainable Growth through Strategic Innovation: Driving Congruence in Capabilities. UK: Edward Elgar Publishing.

Kodama, M. and Shibata, T. (2014). Strategy transformation through strategic innovation capability - A case study of FANUC. $R \& D$ Management, 44(1), pp. $75-103$.

Kodama, M. and Shibata, T. (2016). Developing knowledge convergence through a boundaries vision - A case study of Fujifilm in Japan. Knowledge and Process Management, 23(4), pp. 274-292.

Lee, G. K. (2007). The significance of network resources in the race to enter emerging product markets: The convergence of telephony communications and computer networking, 1989-2001. Strategic Management Journal, 28(1), pp. 17-37.

Mowery, D., Oxley, J. and Silverman, B. (1996). Strategic alliances and interfirm knowledge transfer. Strategic Management Journal, 17(S2), pp. 77-91 (Special Issue: Knowledge and the Firm).

Nelson, R. and Winter, S. (1982). An Evolutionary Theory of Economic Change. Belknap Press.

Nesta, L. and Saviotti, P. (2006). Firm knowledge and market value in biotechnology. Industrial and Corporate Change, 15(4), pp. 625-652.

Nonaka, I. and Takeuchi, H. (1995). The Knowledge-Creating Company. New York, US: Oxford University Press.

Porter, M. E. and Heppelmann, J. E. (2014). How smart, connected products are transforming competition. Harvard Business Review, 92(11), pp. 64-88.

Roco, M. C. (2003). Nanotechnology: Convergence with modern biology and medicine. Current Opinion in Biotechnology, 14(3), pp. 337-346. 
Rodan, S. and Galunic, C. (2004). More than network structure: How knowledge heterogeneity influences managerial performance and innovativeness. Strategic Management Journal, 25(6), pp. 541-562.

Shmulewitz, A., Langer, R. and Patton, J. (2006). Convergence in biomedical technology. Nature Biotechnology, 24(3), pp. 277-280.

Teece, D. J. (1986). Profiting from technological innovation: Implications for integration, collaboration, licensing and public policy. Research Policy, 15(6), pp. 285-305.

Teece, D. J. (2007). Explicating dynamic capabilities: The nature and microfoundations of (sustainable) enterprise performance. Strategic Management Journal, 28(13), pp. 1319-1350.

Teece, D. J. (2012). Dynamic capabilities: Routines versus entrepreneurial action. Journal of Management Studies, 49(8), pp. 1395-1401.

Teece, D. J. (2014). The foundations of enterprise performance: Dynamic and ordinary capabilities in an (economic) theory of firms. The Academy of Management Perspectives, 28(4), pp. 328-352.

Van Den Bosch, F. A., Volberda, H. W. and De Boer, M. (1999). Coevolution of firm absorptive capacity and knowledge environment: Organizational forms and combinative capabilities. Organization Science, 10(5), pp. 551-568.

Zahra, S. (2008). The virtuous cycle of discovery and creation of entrepreneurial opportunities. Strategic Entrepreneurship Journal, 2(3), pp. 243-257 (Special Issue: Opportunities, Organizations, and Entrepreneurship: Theory and Debate).

Zhang, Y. and Li, H. Y. (2010). Innovation search of new ventures in a technology cluster: The role of ties with service intermediaries. Strategic Management Journal, 31(1), pp. 88-109.

\section{Endnote}

1. Changes to the frameworks that arise from the new boundaries between businesses and industries bring about products, product systems and complex systems that integrate these products and systems (Porter and Heppelmann, J. E., 2014). For example, such integrated (complex) systems can be found in the smart houses being promoted by the real estate industry and smart cities being driven by private enterprise (e.g., Fujisawa sustainable smart town, Kashiwa-No-Ha Smart city, and Funabashi smart share town) in Japan. 